
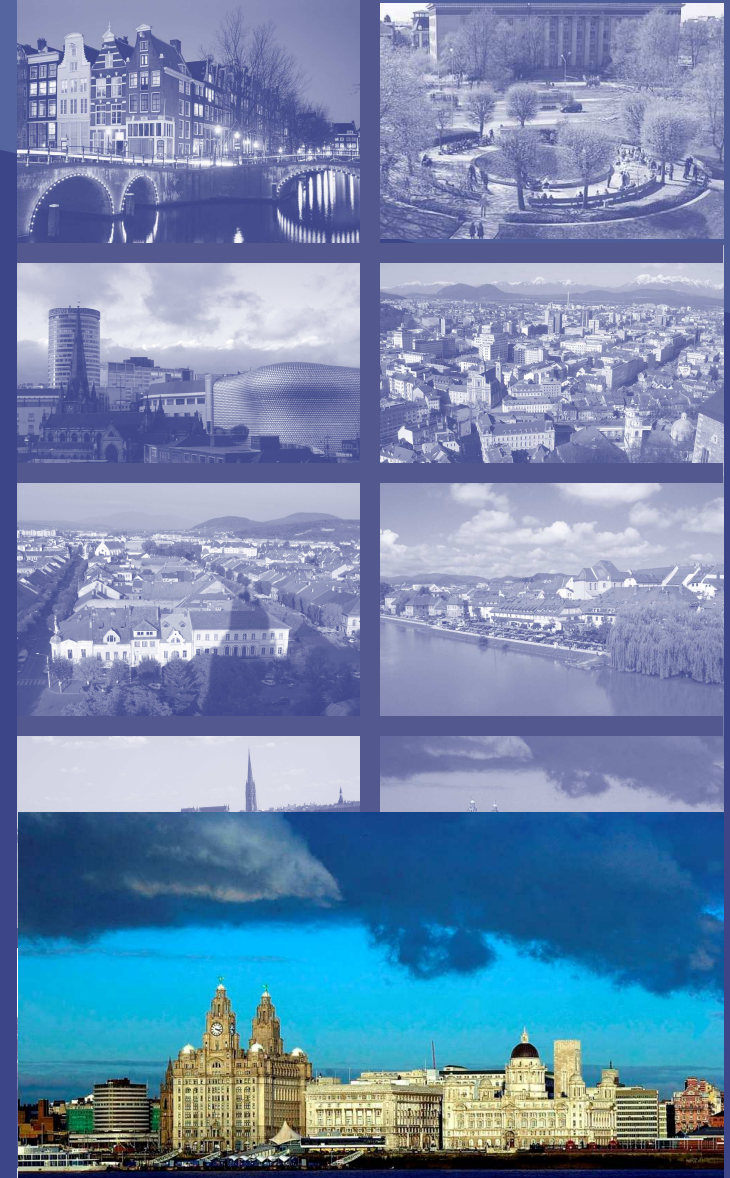

\title{
Health Proffle:
}
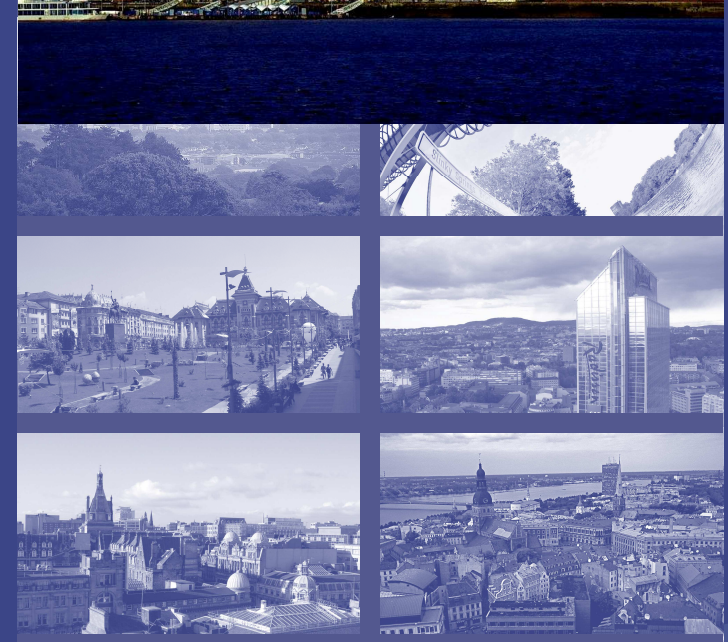

\section{Merseyside,
United Kingdom \\ Merseyside,
United Kingdom}
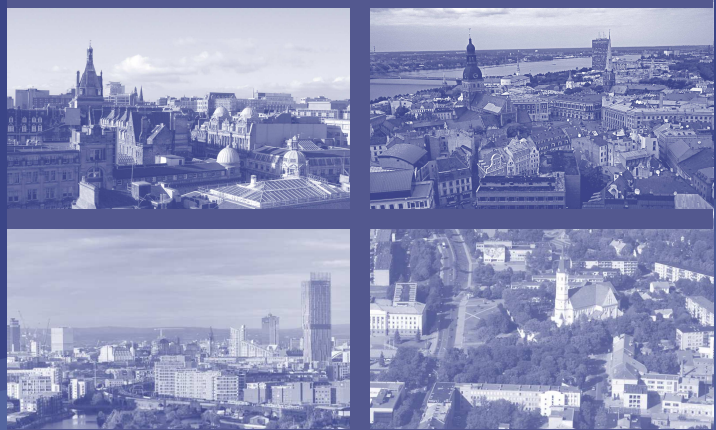

Taking cities to a healthier future
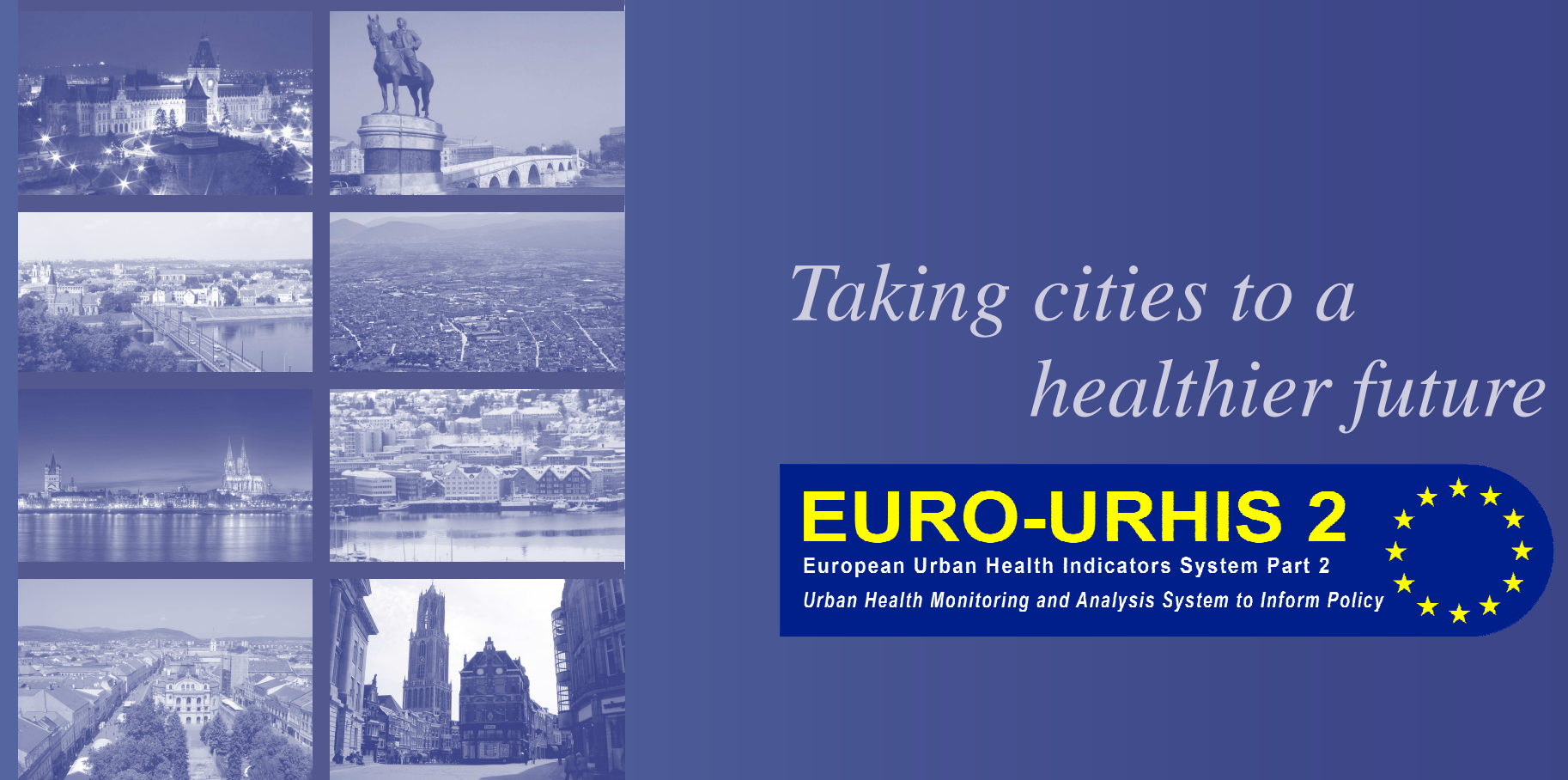


\section{$\square$

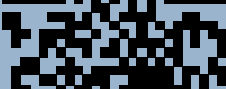 \\ 茄空}

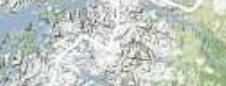

$3 x^{2}+x^{2}$

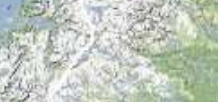

t.
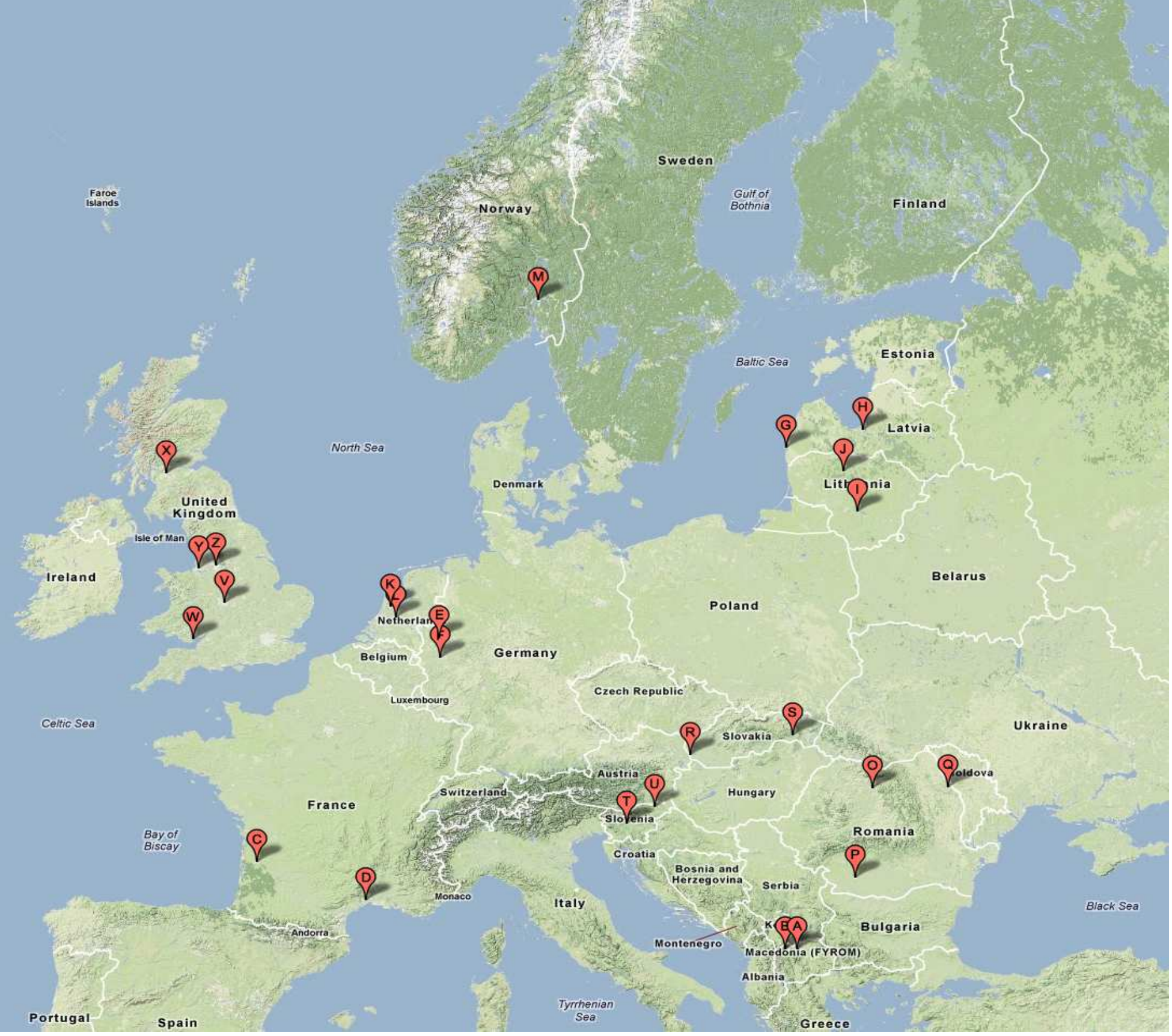

A Skopje, the former Yugoslav Republic of Macedonia

$\mathrm{N}$ Tetovo, the former Yugoslav Republic of Macedonia Bordeaux, France Montpellier, France Oberhausen, Germany Köln, Germany Liepāja, Latvia

H Riga, Latvia

I Kaunas, Lithuania

J Šiauliai, Lithuania

K Amsterdam, The Netherlands

L Utrecht, The Netherlands

M Oslo, Norway
Troms $\varnothing$, Norway Bistrița, Romania Craiova, Romania lași, Romania Bratislava, Slovakia Košice, Slovakia Ljubljana, Slovenia

U Maribor, Slovenia

V Birmingham, United Kingdom

W Cardiff, United Kingdom

$X \quad$ Glasgow, United Kingdom

Y Merseyside, United Kingdom

Z Greater Manchester, United Kingdom 


\section{Depression and anxiety were as often reported in Merseyside as in the other}

EURO-URHIS 2 cities.

All-cause mortality in both males and females is similar in Merseyside compared to other EURO-URHIS 2 cities. Mortality from malignant neoplasms and from diseases of the respiratory system is substantially higher than the overall EURO-URHIS 2 mean. Mortality from diseases of the circulatory system does not differ.

\section{Both heavy episodic drinking in Merseyside youth and binge drinking in adults occur more often than in other EURO-URHIS 2 cities. Smoking in both youth and adults occurs less often in Merseyside than in other EURO-URHIS 2 cities.}

\section{The proportion of overweight or obese adults is higher in Merseyside compared to the overall EURO-URHIS 2 proportion.}

\section{Health and health determinants in Merseyside vary considerably by age, gender and level of education.}

This health profile describes the health situation and associated health determinants in Merseyside compared with those observed in other European urban areas.

Merseyside is one of the urban areas chosen for EURO-URHIS 2 (European Urban Health Indicator System Part 2), a project that aims to identify health problems in urban areas. The EURO-URHIS 2 project describes health and health determinants specific to urban areas in Europe, covering cities in North, East, South, and West Europe. This project may add to information that is already locally available, in that it is the first study to enable reliable comparisons of health status between different cities in Europe. Policy makers can use the information to prioritise topics for urban health policy and for interventions in an evidence-based way.

EURO-URHIS 2 gathered information by collecting data from routinely available registration data, and by conducting youth and adult surveys at the end of 2010. In total, data from 26 urban areas in Europe were available for between-city comparisons and benchmarking.

The routinely available registration data relate to the most recently available year (2002-2008). The youth survey was a school-based survey of 14-16 year olds. In Merseyside, 1,128 students completed a valid questionnaire. The adult survey was carried out involving a representative sample of adults aged 19-64 and 65+. In Merseyside, 1,147 19-64 year olds and 1,084 65+ year olds completed valid questionnaires.

Data collection in Merseyside was conducted in all five boroughs: Halton \& St Helens, Knowsley, Liverpool, Sefton, and Wirral.

More detailed information on the justification of methods and instruments that were used, as well as response rates, selection of cities and indicators, and statistical methodology, can be found on our websites: www.urhis.eu and http://results.urhis.eu. The websites also provide data from other participating urban areas and comparisons between specific cities can be made. 
not statistically significantly different from EURO-URHIS 2 mean

statistically significantly different from EURO-URHIS 2 mean

Lowest in
EURO-
URHIS 2

The graphs in this health profile show the health status of the urban area compared to other EURO-URHIS 2 urban areas. The whiskers represent the lowest and highest value within the EURO-URHIS 2 project on a scale of 0 to $100 \%$. The grey bar represents the $25^{\text {th }}$, $50^{\text {th }}$, and $75^{\text {th }}$ percentile. The urban area value is shown as a diamond, which is blue when the value is not statistically significantly different from the EURO-URHIS 2 mean and red when the difference is statistically significant (at the $5 \%$ level).

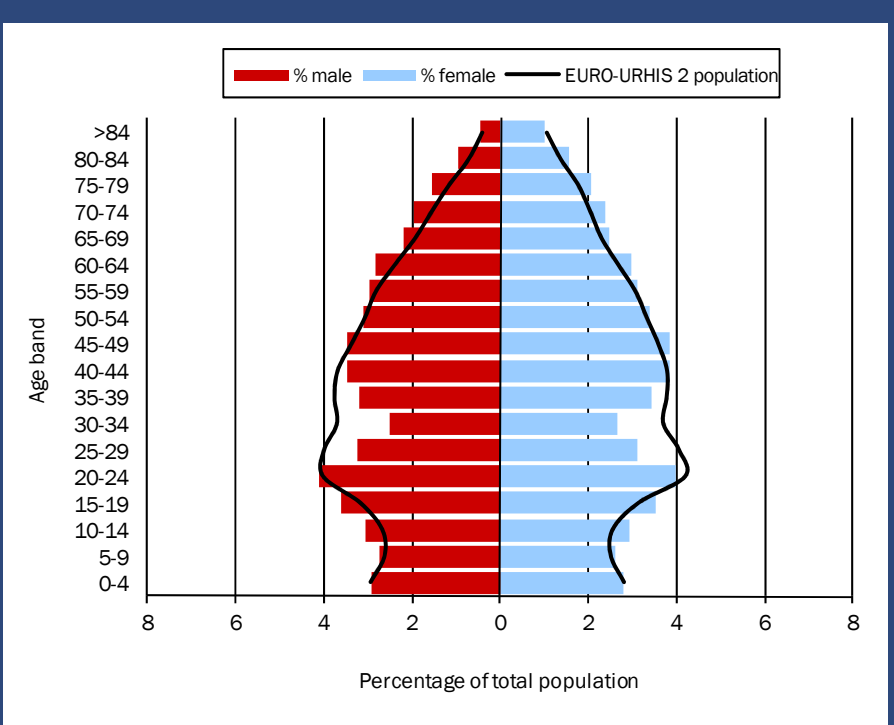

Figure 1. Age distribution

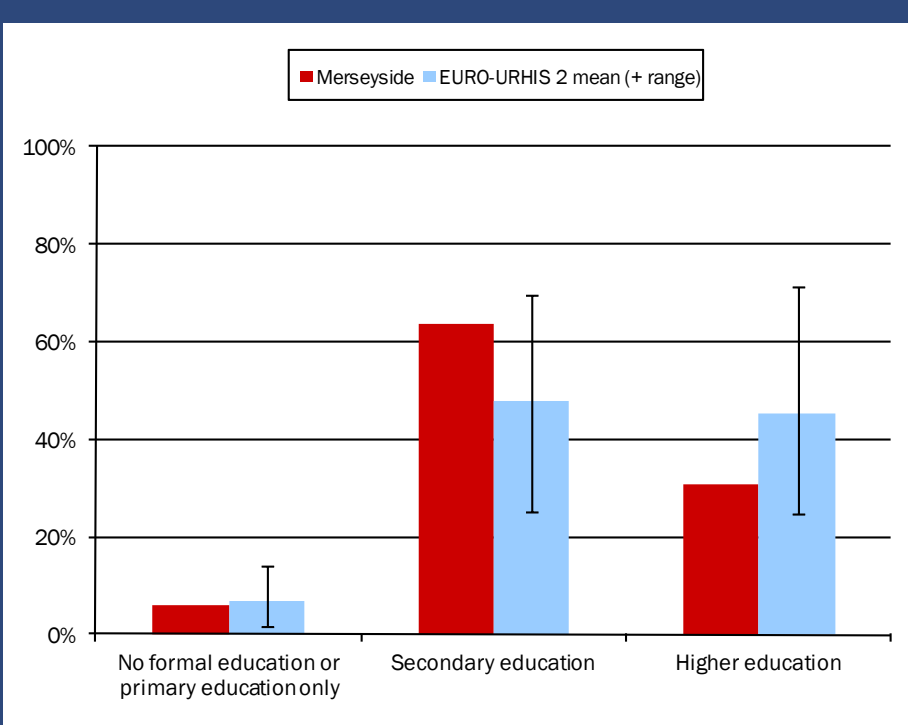

Figure 2. Level of education

Differences in health status may possibly be explained by age and education. Figures 1 and 2 show the age distribution and level of education in Merseyside compared to the other EURO-URHIS 2 urban areas. Age differences between adults from Merseyside and other EURO-URHIS 2 cities could explain the significantly different level of women who have undergone a cervical smear test within the past three years. Education did not explain any observed differences in the adult survey between Merseyside and other EURO-URHIS 2 urban areas.

\section{DISCLAIMER}

To achieve maximum quality of the data, all instruments used were based on knowledge of earlier studies and expert consultations, and were piloted, validated, and optimised. The survey questionnaires of EURO-URHIS 2 were based on already existing, validated instruments; selected indicators were as little culturally sensitive as possible. Questionnaires were translated in the local language(s) and, for validation purposes, back-translated into English. Youth survey response rates were generally very high. In the adult survey, a minimum response rate of $30 \%$ was required to be included for benchmarking. Despite all our efforts, and as in any survey, the point estimates for certain health indicators in your urban area may deviate from other estimates, and may not be comparable to other local information due to differences in study methodology and indicator definitions. If you would like further information regarding the methodology, please see our websites: http://www.urhis.eu and http://results.urhis.eu. 


\section{Health-related Characteristics of Merseyside}

\begin{tabular}{|c|c|c|c|c|c|c|c|c|c|c|}
\hline & \multirow{2}{*}{ Indicator } & \multirow{2}{*}{ Merseyside } & \multirow{2}{*}{$\begin{array}{l}\text { United } \\
\text { Kingdom }\end{array}$} & \multicolumn{5}{|c|}{ EURO-URHIS 2 range (percentiles) } & \multirow{2}{*}{$\begin{array}{c}\text { EURO- } \\
\text { URHIS } 2 \\
\text { mean }\end{array}$} & \multirow{2}{*}{$\mathbf{N}$} \\
\hline & & & & $\min$ & 25th & 50 th & 75th & $\max$ & & \\
\hline \multirow{7}{*}{ 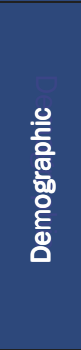 } & 1. Population size $(x 1,000)$ & 1,342 & 61,192 & 67 & 264 & 406 & 708 & 2,565 & 570 & 23 \\
\hline & 2. Population density & 2,110 & 251 & 27 & 1,115 & 2,040 & 2,840 & 4,580 & 1,974 & 24 \\
\hline & 3. Population aged 0-19 years & $24 \%$ & $24 \%$ & $17 \%$ & $20 \%$ & $22 \%$ & $24 \%$ & $28 \%$ & $22 \%$ & 23 \\
\hline & 4. Population aged $65+$ years & $17 \%$ & $16 \%$ & $7 \%$ & $11 \%$ & $14 \%$ & $15 \%$ & $20 \%$ & $14 \%$ & 23 \\
\hline & 5. Live births & 59 & 63 & 39 & 45 & 52 & 58 & 75 & 53 & 24 \\
\hline & 6. Teenage pregnancies & 27 & 26 & 4 & 7 & 11 & 20 & 33 & 14 & 18 \\
\hline & 7. Pregnancies after age 35 & 29 & 34 & 7 & 18 & 23 & 33 & 59 & 28 & 18 \\
\hline \multirow{4}{*}{ 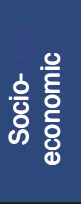 } & 8. Unemployment (age 19-64) & $5.0 \%$ & - & $3.6 \%$ & $4.0 \%$ & $4.9 \%$ & $7.2 \%$ & $10.2 \%$ & $5.8 \%$ & 16 \\
\hline & 9. Higher level education & $31 \%$ & - & $25 \%$ & $33 \%$ & $45 \%$ & $53 \%$ & $72 \%$ & $45 \%$ & 16 \\
\hline & 10. Not enough money & $13 \%$ & - & $5 \%$ & $11 \%$ & $16 \%$ & $22 \%$ & $61 \%$ & $21 \%$ & 16 \\
\hline & 11. Low family wealth & $8 \%$ & - & $5 \%$ & $7 \%$ & $13 \%$ & $21 \%$ & $44 \%$ & $16 \%$ & 20 \\
\hline \multirow{4}{*}{ 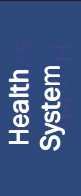 } & 12. MMR vaccinated & $83 \%$ & $86 \%$ & $83 \%$ & $88 \%$ & $94 \%$ & $97 \%$ & $100 \%$ & $93 \%$ & 19 \\
\hline & 13. DTP vaccinated & $87 \%$ & $92 \%$ & $83 \%$ & $93 \%$ & $95 \%$ & $97 \%$ & $99 \%$ & $94 \%$ & 19 \\
\hline & 14. Cervical smear test & $59 \%$ & - & $41 \%$ & $62 \%$ & $70 \%$ & $76 \%$ & $83 \%$ & $68 \%$ & 16 \\
\hline & 15. Cholesterol measurement & $43 \%$ & - & $23 \%$ & $42 \%$ & $47 \%$ & $52 \%$ & $64 \%$ & $47 \%$ & 16 \\
\hline \multirow{4}{*}{ 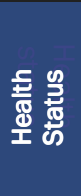 } & 16. Life expectancy - male & 75.6 & 77.8 & 68.2 & 71.0 & 75.3 & 76.1 & 77.0 & 73.6 & 18 \\
\hline & 17. Life expectancy - female & 80.2 & 81.9 & 76.2 & 78.5 & 80.2 & 81.0 & 82.0 & 79.7 & 18 \\
\hline & 18. Infant mortality & 5.4 & 4.6 & 1.3 & 3.5 & 4.9 & 5.7 & 9.4 & 5.0 & 24 \\
\hline & 19. Low birth weight & $7.7 \%$ & $7.1 \%$ & $2.7 \%$ & $5.2 \%$ & $6.6 \%$ & $8.1 \%$ & $11.8 \%$ & $6.7 \%$ & 22 \\
\hline
\end{tabular}

\section{Table 1. Health-related characteristics of Merseyside}

Source. Indicators 1-7, 12-13, and 16-19: routinely available registration data; indicators 8-10 and 14-15: adult survey; indicator 11: youth survey. Missing data are indicated by “-“.

$\mathrm{N}=$ number of urban areas that were able to collect data on the specific indicator.

1. number of inhabitants; 2. number of inhabitants per $\mathrm{km}^{2} ; 3 . \%$ of inhabitants aged 0-19 years; 4 . \% of inhabitants aged 65 years or older; 5 . number of births per 1,000 women aged 15-44 years; 6 . number of births per 1,000 women aged 15-19 years; 7 . number of births per 1,000 women aged 35-44 years; 8. \% of adults aged 19-64 years who are unemployed; 9. \% of adults who attained higher level education; $10 . \%$ of adults who do not have enough money for daily expenses; 11 . \% of youth who live in a low wealth family, as defined by a FAS (Family Affluence Scale) score of $\leq 3$; 12 . \% of population who have completed measles, mumps, and rubella (MMR) vaccination courses before school-age; 13 . \% of population who have completed diphtheria, tetanus, and poliomyelitis (DTP) vaccination courses before school-age; 14. \% of adult women who have undergone a cervical smear test within the past three years; $15 . \%$ of adults who had their serum cholesterol measured within the last year; 16-17. number of years that a newborn is expected to live if current mortality rates continue to apply; 18 . annual number of deaths of children under one year of age, per 1,000 births; $19 . \%$ of total live births weighing less than 2,500 grams

Compared to other cities in EURO-URHIS 2, Merseyside is an urban area with average population density and a relatively small population of young adults aged 25-39 years. The number of annual live births in Merseyside is higher than the overall EURO-URHIS 2 mean. Teenage pregnancies are relatively common.

The percentage of inhabitants with higher level education in Merseyside (31\%) is relatively low compared to the overall EURO -URHIS 2 mean. The proportion of adults who reported to not have enough money for daily expenses (13\%) is significantly lower than in the other EURO-URHIS 2 urban areas. The percentage of youth that reported to live in poor families (8\%) is significantly lower than the EURO-URHIS 2 mean.

The proportion of people who have completed MMR and DTP vaccination courses is lower than in other EURO-URHIS 2 urban areas. Significantly less women have undergone a cervical smear test compared to the overall EURO-URHIS 2 average. Also cholesterol measurements were less often reported in Merseyside.

Life expectancy at birth is an indicator for the general health status of a population. In Merseyside, male life expectancy is 75.6 years and female life expectancy is 80.2 years, which are both similar to the overall averages in EURO-URHIS 2.

Infant mortality is an indicator for population health and quality of health care services. With an infant mortality rate of 5.4 per 1,000 live births, Merseyside is comparable to other EURO-URHIS 2 urban areas.

At the population level, low birth weight is an indicator for pregnancy conditions and perinatal care. Low birth weight can at the individual level also result in health problems later in life. Of all newborns in Merseyside, $7.7 \%$ had a low birth weight, which is comparable to the overall EURO-URHIS 2 mean. 
YOUTH HEALTH STATUS

\begin{tabular}{|c|c|c|c|c|c|}
\hline \multirow{2}{*}{\multicolumn{2}{|c|}{ Indicator }} & \multirow{2}{*}{ Merseyside } & EURO-URHIS 2 range (percentiles) & \multirow{2}{*}{$\begin{array}{l}\text { EURO- } \\
\text { URHIS } 2 \\
\text { mean }\end{array}$} & \multirow{2}{*}{$\mathbf{N}$} \\
\hline & & & $50 \%$ & & \\
\hline \multirow{4}{*}{ 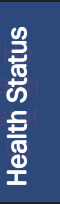 } & 1. Good self-perceived health & $83 \%$ & $\mapsto \square-1$ & $92 \%$ & 20 \\
\hline & 2. Elevated risk of psychological problems & $24 \%$ & $\longmapsto \square \square$ & $20 \%$ & 20 \\
\hline & 3. Psychosomatic symptoms & $14 \%$ & $-\square \rightarrow$ & $10 \%$ & 20 \\
\hline & 4. Low back pain & $36 \%$ & $\longmapsto \square$ & $42 \%$ & 20 \\
\hline \multirow{12}{*}{ 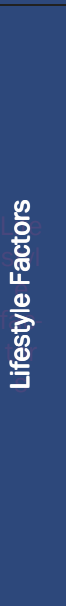 } & 5. Overweight and obesity & - & $\mapsto \square-1$ & $13 \%$ & 15 \\
\hline & 6. Physical activity $\geq 2$ hours/week & $55 \%$ & $\longrightarrow$ & $50 \%$ & 20 \\
\hline & 7. Regular fruit consumption & $38 \%$ & $\mapsto-\square$ & $49 \%$ & 20 \\
\hline & 8. Regular vegetable/salad consumption & $47 \%$ & $\mapsto \longmapsto$ & $52 \%$ & 20 \\
\hline & 9. Regular tooth brushing & $83 \%$ & $\longmapsto \square \longrightarrow$ & $72 \%$ & 20 \\
\hline & 10. Frequently watching television & $63 \%$ & $\longmapsto \square \longrightarrow$ & $60 \%$ & 20 \\
\hline & 11. Daily smoking & $7 \%$ & $\mapsto \square \square$ & $12 \%$ & 20 \\
\hline & 12. First smoking $\leq 13$ years & $14 \%$ & $\longmapsto \square \square$ & $24 \%$ & 20 \\
\hline & 13. Heavy episodic drinking & $55 \%$ & $\longmapsto$ & $33 \%$ & 20 \\
\hline & 14. First alcohol $\leq 13$ years & $61 \%$ & + & $53 \%$ & 19 \\
\hline & 15. Ever used cannabis & $22 \%$ & $\longmapsto$ & $16 \%$ & 20 \\
\hline & 16. Unprotected sexual intercourse & $5 \%$ & $-\mathrm{E}-1$ & $4 \%$ & 20 \\
\hline \multirow{3}{*}{ 客芯 } & 17. Crime in area & $48 \%$ & $\longmapsto \square$ & $35 \%$ & 20 \\
\hline & 18. Involved in traffic accident & $6 \%$ & $1-1-1$ & $7 \%$ & 18 \\
\hline & 19. Being bullied & $3 \%$ & 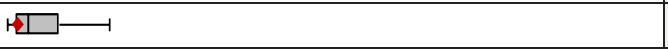 & $7 \%$ & 20 \\
\hline
\end{tabular}

Table 2. Health status and determinants in youth (14-16 years)

Source. Indicators 1-19: youth survey. Missing data are indicated by “-“.

$\mathrm{N}=$ number of urban areas that were able to collect data on the specific indicator.

1. \% of youth who perceive their health as good, very good, or excellent; 2 . \% of youth with an overall Strengths and Difficulties Questionnaire (SDQ) score of 20 or higher; 3. \% of youth who reported a lot of headaches, stomach aches, or sickness during the past six months; 4 . \% of youth who experienced low back pain during the past month; 5 . \% of youth overweight or obese according to the international BMI cut-offs; 6 . \% of youth who participate in vigorous physical activity for more than two hours per week in their free time; $7 . \%$ of youth who eat fruit on most days of the week; 8. \% of youth who eat vegetables and/or salads on most days of the week; 9 . \% of youth who brush their teeth more than once a day; 10 . \% of youth who watch television for more than two hours on weekdays; 11 . \% of youth who smoke tobacco every day; $12 . \%$ of youth who reported first smoking at $\leq 13$ years; 13 . $\%$ of youth who drank five or more units of alcohol on one occasion during the past 30 days; 14 . \% of youth who reported first drinking alcohol at $\leq 13$ years; 15 . \% of youth who ever used cannabis; 16. \% of the total youth population who did not use a condom the last time they had sexual intercourse; $17 . \%$ of youth who reported presence of crime, violence, or vandalism in the area where they live; 18 . \% of youth who had a road traffic accident resulting in injury over the past 12 months; $19 . \%$ of youth who have been bullied at least twice in the past couple of months

\section{Health Status and Determinants in Youth}

Table 2 gives an overview of the health status and determinants in Merseyside youth, as reported from the survey. Self-perceived health is a measure of adolescent well-being. 83\% of youth in Merseyside perceived their health to be (very) good or excellent, which is significantly lower than the overall EURO-URHIS 2 proportion. In Merseyside, a significantly higher proportion of youth were identified with an elevated risk of psychological problems (24\%), compared to the overall EURO-URHIS 2 proportion. Psychosomatic symptoms like headaches, stomach aches, and sickness are reported more often in Merseyside, whereas low back pain was reported less often.

Childhood obesity is related to a higher risk of obesity, disability, and premature death later in life. Physical activity can contribute to maintaining a healthy weight and preventing the occurrence of chronic conditions. Furthermore, physical activity is associated with psychological benefits and with a better school performance in young people. The proportion of youth who reported participation in vigorous physical activity for two or more hours per week is significantly higher in Merseyside (55\%), compared to the overall EURO-URHIS 2 proportion. A healthy diet can lower the risk of obesity. Regular consumption of fruit and vegetables occurs less frequently in Merseyside than in other EURO-URHIS 2 urban areas.

Significantly more students in Merseyside brush their teeth at least twice a day compared to other EURO-URHIS 2 cities. 
Initiation of smoking and drinking alcohol at a young age is a strong predictor of smoking during adulthood and of later problems with alcohol. Smoking at the age of 13 or younger occurs significantly less often in Merseyside than in other EURO-URHIS 2 cities, whereas drinking alcohol at the age of 13 or younger occurs significantly more often. The proportion of youth in Merseyside who smoke daily (7\%) is lower than the overall EURO-URHIS 2 proportion. Heavy episodic drinking of five or more units of alcohol on one occasion was reported significantly more often in Merseyside (55\%) compared to the total EURO-URHIS 2 population.
Regular cannabis use in young people can lead to impaired cognitive development. 22\% of youth in Merseyside have ever used cannabis, which is higher than the overall EURO-URHIS 2 proportion.

Neighbourhood crime, violence, or vandalism was significantly more often reported by youth in Merseyside (48\%) compared to other cities. The proportion of youth who were victims of bullying in the past couple of months was significantly lower.

\section{ADULT HEALTH STATUS}

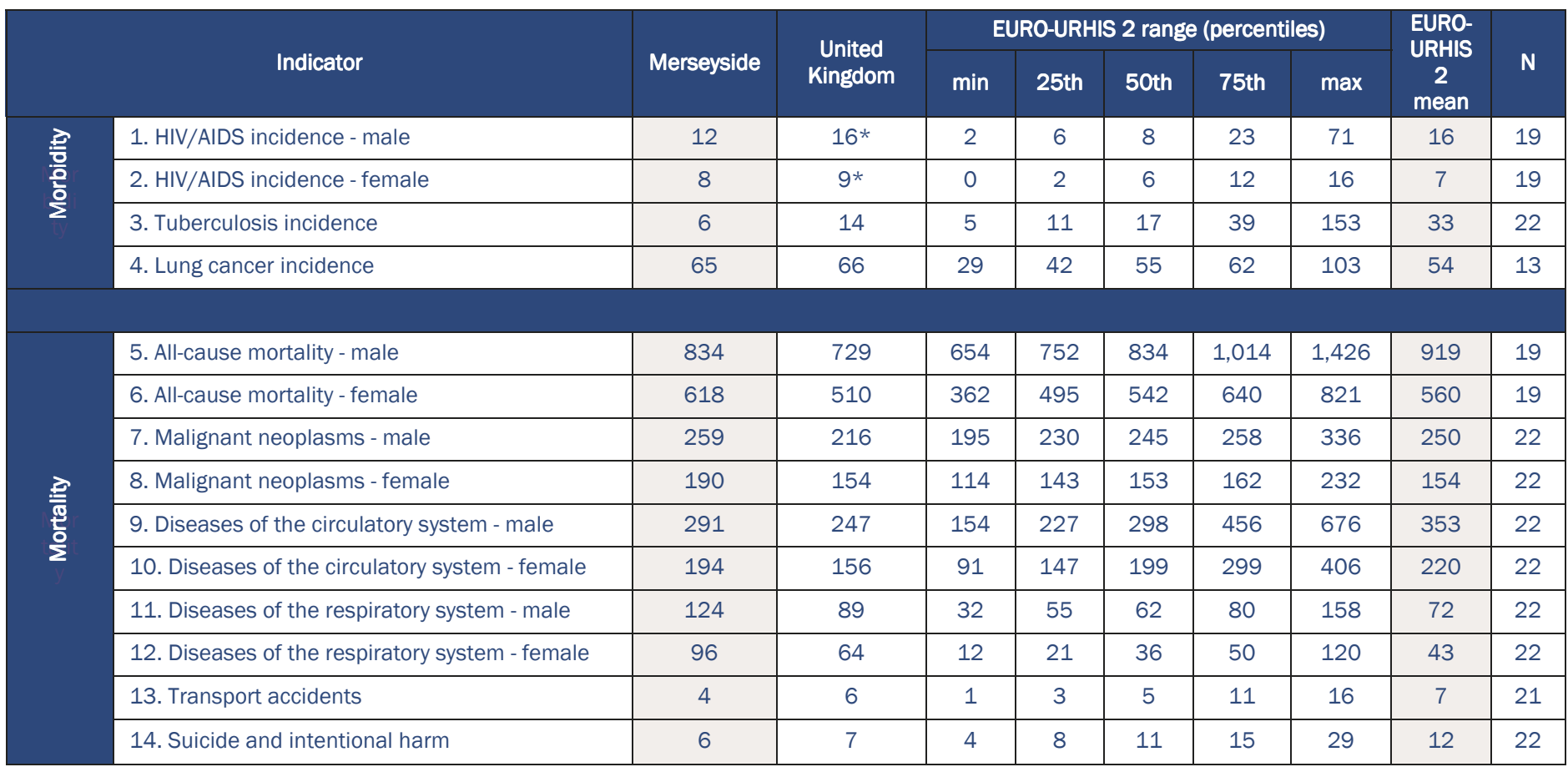

\section{Table 3. Morbidity and mortality}

Source. Indicators 1-14: routinely available registration data. Missing data are indicated by “-“.

* Country level data include HIV incidence only.

$\mathrm{N}=$ number of urban areas that were able to collect data on the specific indicator.

1-4. Number of newly diagnosed cases with a specific disease per 100,000 persons per year; 5-6. All-cause mortality rate per 100,000 persons per year (standardised on European population); 7-14. Mortality rate due to a specific cause per 100,000 persons per year (standardised on European population)

\section{Health Status and Determinants in Adults}

The health status of a population can be assessed by using a number of parameters, such as those referring to acute and chronic disease, mortality, psychological well-being, and self-perceived health. Table 3 and indicators $1-8$ of Table 4 show the overall health status among adults in Merseyside, compared to other cities in Europe. The results show that in Merseyside the incidence of tuberculosis is lower than the overall average in all EURO-URHIS 2 urban areas, whereas the incidence of lung cancer is higher.

All-cause mortality in both males and females is comparable to other cities. Mortality from malignant neoplasms and from diseases of the respiratory system is substantially higher, whereas mortality from suicide and intentional harm occurs less often. 


\section{Health Status and Determinants in Adults (continued)}

\begin{tabular}{|c|c|c|c|c|c|}
\hline & \multirow{2}{*}{ Indicator } & \multirow{2}{*}{ Merseyside } & EURO-URHIS 2 range (percentiles) & \multirow{2}{*}{$\begin{array}{c}\text { EURO- } \\
\text { URHIS } 2 \\
\text { mean }\end{array}$} & \multirow{2}{*}{$\mathbf{N}$} \\
\hline & & & $100 \%$ & & \\
\hline \multirow{8}{*}{ 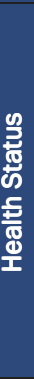 } & 1. (Very) good self-perceived health & $71 \%$ & $\square 10$ & $64 \%$ & 16 \\
\hline & 2. Psychological problems & $23 \%$ & $\longmapsto$ & $23 \%$ & 16 \\
\hline & 3. Depression/anxiety & $10 \%$ & 世— & $9 \%$ & 16 \\
\hline & 4. Cardiovascular disease (age 65+) & $13 \%$ & $\longmapsto$ & $18 \%$ & 16 \\
\hline & 5. Cancer & $2 \%$ & H & $2 \%$ & 16 \\
\hline & 6. Asthma or bronchitis & $6 \%$ & 缯一 & $7 \%$ & 16 \\
\hline & 7. Long-standing illness with restrictions & $22 \%$ & $\square-\square$ & $28 \%$ & 16 \\
\hline & 8. Low back pain & $36 \%$ & $\longmapsto$ & $45 \%$ & 16 \\
\hline \multirow{8}{*}{ 然 } & 9. Regular consumption of fruit/vegetables & $63 \%$ & $\square \square$ & $53 \%$ & 16 \\
\hline & 10. Regular breakfast & $84 \%$ & $\longmapsto \square \longrightarrow$ & $78 \%$ & 16 \\
\hline & 11. Being physically active $\geq$ twice a week & $47 \%$ & $\longmapsto$ & $46 \%$ & 16 \\
\hline & 12. Overweight and obesity & $57 \%$ & $\longmapsto \square$ & $50 \%$ & 16 \\
\hline & 13. Daily smoking & $15 \%$ & $\square$ & $18 \%$ & 16 \\
\hline & 14. Passive smoking by non-smokers & $11 \%$ & 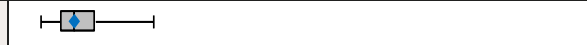 & $13 \%$ & 16 \\
\hline & 15. Binge drinking & $32 \%$ & $\mapsto \square \longrightarrow$ & $17 \%$ & 16 \\
\hline & 16. Cannabis last year (age 19-64) & $5 \%$ & H䧃— & $5 \%$ & 16 \\
\hline \multirow{5}{*}{$\Phi$} & 17. Green areas suitable for recreational activities & $87 \%$ & $\longmapsto \square \longrightarrow$ & $84 \%$ & 16 \\
\hline & 18. Belonging to immediate neighbourhood & $62 \%$ & $\longmapsto \square \square$ & $54 \%$ & 16 \\
\hline & 19. Social cohesion in neighbourhood & $54 \%$ & $\longmapsto$ & $52 \%$ & 16 \\
\hline & 20. Exposure to severe noise & $11 \%$ & $\mapsto \square-$ & $14 \%$ & 16 \\
\hline & 21. Damp spots or mould at home & $32 \%$ & $\longmapsto-1$ & $27 \%$ & 16 \\
\hline
\end{tabular}

Table 4. Health status and determinants in adults (19 years and older)

Source. Indicators 1-21: adult survey. Missing data are indicated by “- “

$\mathrm{N}=$ number of urban areas that were able to collect data on the specific indicator.

1. \% of adults who perceive their health to be good or very good; 2. \% of adults with a score of four or more on the General Health Questionnaire (GHQ); 3 . \% of adults who reported to be diagnosed with or treated for anxiety or depression during the past year; 4 . \% of adults aged 65 years and older who were diagnosed with or treated for heart attack, angina, or heart failure during the past year; 5 . \% of adults who were diagnosed with or treated for (any kind of malignant) cancer during the past year; $6 . \%$ of adults who were diagnosed with or treated for bronchial asthma or chronic bronchitis during the past year; 7. $\%$ of adults who suffer from any long-standing illness, long-standing effect from injury, disability, or other long-standing condition; 8 . \% of adults who had low back pain longer than one day in the past month; $9 . \%$ of adults who eat, on average, four or more portions of fruit and/or vegetables per day; $10 . \%$ of adults who have breakfast at least four times a week; 11. \% of adults who are physically active for at least 30 minutes twice a week or more; $12 . \%$ of adults overweight or obese, defined as a BMI of $\geq 25 \mathrm{~kg} / \mathrm{m}^{2} ; 13 . \%$ of adults who smoke every day; 14. \% of non-smokers who are exposed to second-hand smoking inside their home; 15. \% of adults who drink six or more portions of alcohol on one occasion, at least once a week (men) or at least once a month (women); 16. \% of adults aged 19-64 years who used cannabis during the past year; $17 . \%$ of adults who perceive the green areas in their neighbourhood to be suitable for active recreational activities; 18. \% of adults who feel that they belong to their immediate neighbourhood; 19 . \% of adults who perceive their neighbourhood to be socially cohesive; $\mathbf{2 0}$. \% of adults who were exposed to severe noise from outdoors during the past 12 months; $\mathbf{2 1 .} \%$ of adults who had wet or damp spots and/or mould or mildew inside their homes (other than in basements) within the past 12 months

The proportion of people in Merseyside who perceive their health to be good or very good (71\%) is higher than the average in the other urban areas in EURO-URHIS 2. The percentage of adults who reported psychological problems in Merseyside (23\%) is comparable to other urban areas in EURO-URHIS 2. Cardiovascular disease in the elderly, long-standing illness with restrictions, and low back pain were significantly less often reported.

Several lifestyle factors and environmental determinants can affect health (Table 4, indicators 9-21). Daily smoking, for instance, increases the risk of cancer, particularly lung cancer. Smokers are also at far greater risk of developing heart disease, stroke, and emphysema. Binge drinking is associated with many health problems, which include injuries and violence, sexually transmitted diseases, alcohol dependency, liver disease, and neurological damage. The percentage of persons who smoke daily $(15 \%)$ is significantly lower than in other EURO-URHIS 2 cities. The proportion of adults who regularly drink more than six units of alcohol (32\%) is significantly higher in Merseyside compared to the overall EURO-URHIS 2 mean.

Being overweight and obese are important determinants of death worldwide. They increase the risk of cardiovascular diseases, diabetes, musculoskeletal disorders, and some cancers. In Merseyside, $57 \%$ of the adults are overweight or obese, which is higher than the overall EURO-URHIS 2 proportion. Being overweight and obese are related to lack of regular physical activity. Being physically active reduces the risk of hypertension, coronary heart disease, stroke, diabetes, breast and colon cancer, depression, and the risk of injury caused by falls. The proportion of adults in Merseyside physically active more than twice a week (47\%) does not differ from the total EURO-URHIS 2 proportion. A healthy diet can lower the risk of obesity. 
Adults in Merseyside more frequently eat fruit and vegetables and a regular breakfast was significantly more often reported.

Psychological well-being may be influenced both by the availability of green spaces in the neighbourhood that are suitable for recreational activities and by aspects of social cohesion. In Merseyside, $87 \%$ perceived their green spaces to be suitable for recreational activities, whereas this proportion is significantly lower in other cities. The percentage of adults who perceived their neighbourhood to be socially cohesive was $54 \%$, which is similar to the overall EURO-URHIS 2 average. A significantly higher percentage of people feel that they belong to their immediate neighbourhood. Exposure to severe noise from outdoors was less often reported in Merseyside compared to other cities, whereas the presence of damp spots or mould and mildew inside their homes occurred more often.

\begin{tabular}{|c|c|c|c|c|c|c|c|c|}
\hline \multicolumn{2}{|r|}{ Indicator } & \multirow[b]{2}{*}{ 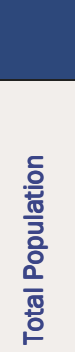 } & \multicolumn{2}{|c|}{ Age } & \multicolumn{2}{|c|}{ Gender } & \multicolumn{2}{|c|}{ Education level } \\
\hline & & & $\begin{array}{l}\text { பे } \\
1 \\
\text { g }\end{array}$ & $\stackrel{+}{\stackrel{+}{0}}$ & $\frac{\frac{0}{\pi}}{\sum}$ & 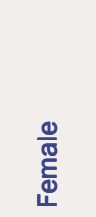 & 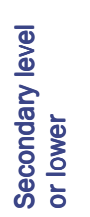 & $\begin{array}{l}\bar{\Phi} \\
\frac{\bar{d}}{\bar{\Phi}} \\
\overline{\frac{\Phi}{\mathrm{w}}} \\
\overline{\mathbf{I}}\end{array}$ \\
\hline \multirow{3}{*}{ 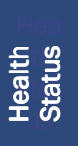 } & 1. (Very) good self-perceived health & $71 \%$ & $76 \% *$ & $55 \% *$ & $70 \%$ & $72 \%$ & $66 \% *$ & $86 \% *$ \\
\hline & 2. Psychological problems & $23 \%$ & $24 \% *$ & $18 \% *$ & $20 \% *$ & $25 \% *$ & $23 \%$ & $21 \%$ \\
\hline & 3. Long-standing illness with restrictions & $22 \%$ & $16 \% *$ & $42 \% *$ & $23 \%$ & $21 \%$ & $26 \% *$ & $10 \% *$ \\
\hline \multirow{6}{*}{ 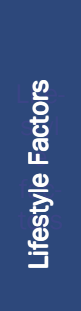 } & 4. Overweight and obesity & $57 \%$ & $55 \% *$ & $61 \% *$ & $62 \% *$ & $52 \% *$ & $61 \% *$ & $46 \% *$ \\
\hline & 5. Daily smoking & $15 \%$ & $17 \% *$ & $10 \% *$ & $17 \%$ & $14 \%$ & $18 \% *$ & $10 \% *$ \\
\hline & 6. Binge drinking & $32 \%$ & $35 \% *$ & $21 \% *$ & $35 \% *$ & $29 \% *$ & $34 \%$ & $29 \%$ \\
\hline & 7. Regular consumption of fruit/vegetables & $63 \%$ & $61 \% *$ & $69 \% *$ & $56 \% *$ & $69 \% *$ & $59 \% *$ & $71 \% *$ \\
\hline & 8. Being physically active $\geq$ twice a week & $47 \%$ & $48 \%$ & $44 \%$ & $51 \% *$ & $43 \% *$ & $44 \% *$ & $54 \% *$ \\
\hline & 9. Social cohesion in neighbourhood & $54 \%$ & $51 \% *$ & $63 \% *$ & $50 \% *$ & $57 \% *$ & $53 \%$ & $57 \%$ \\
\hline
\end{tabular}

Table 5. Health and health determinants by demographic groups in Merseyside

Source. Adult survey.

Indicators are defined in Table 4. Missing data are indicated by “-“.

* Statistically significant difference between subgroups at the 5\% level.

\section{Health and Health Determinants by Demographic Groups}

Health and health determinants can vary considerably as according to age, gender, and education. Table 5 subdivides a selection of important health indicators in Merseyside by subgroup: respondents aged 19-64 and 65+ years, males and females, and adults who achieved secondary level education or lower and higher level education.

Respondents aged 19-64 years in Merseyside more often perceived their health to be good or very good, were less often restricted by a long-standing illness, and had a lower tendency to be overweight or obese, compared to older respondents. However, younger respondents more frequently experienced psychological problems, were more likely to be daily smokers, more commonly drank six or more portions of alcohol on one occasion, less frequently ate fruit and vegetables, and less often perceived their neighbourhood as being socially cohesive. Physical activity did not differ by age.

Men and women in Merseyside did not differ in self-perceived health and restrictions due to long-standing illness. Neither did the percentage of daily smoking differ between sexes. Men in Merseyside less frequently experienced psychological problems and more often engaged in physical activity compared to women. However, men in Merseyside had a greater tendency to be overweight or obese, more commonly drank six or more portions of alcohol on one occasion, less frequently ate fruit and vegetables, and less often perceived their neighbourhood as being socially cohesive compared to women.

Adults in Merseyside who attained secondary level education or lower less often perceived their health to be good or very good and were more often restricted by a long-standing illness than adults with higher level education. Lower educated respondents had a greater tendency to be overweight or obese, were more likely to be daily smokers, less frequently ate fruit and vegetables, and less often engaged in physical activity. The occurrence of psychological problems, binge drinking and perceived social neighbourhood cohesion did not differ by education level. 


\section{Healthy Life Expectancy}

Males Aged 15

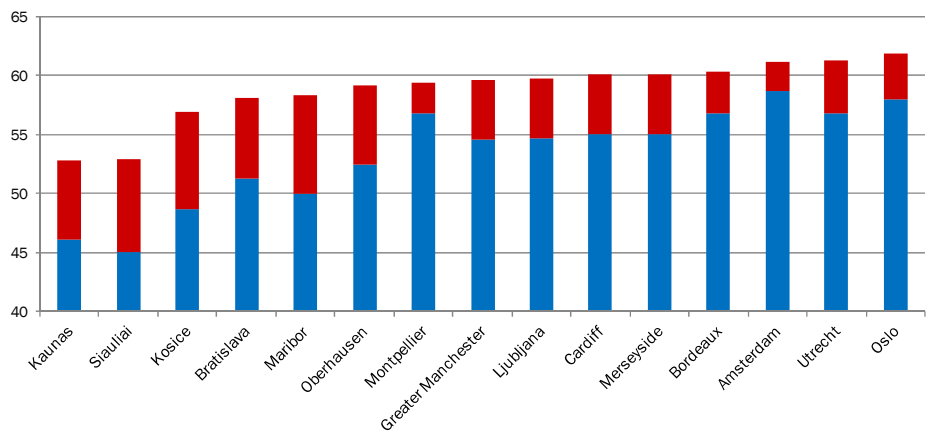

Males Aged 60

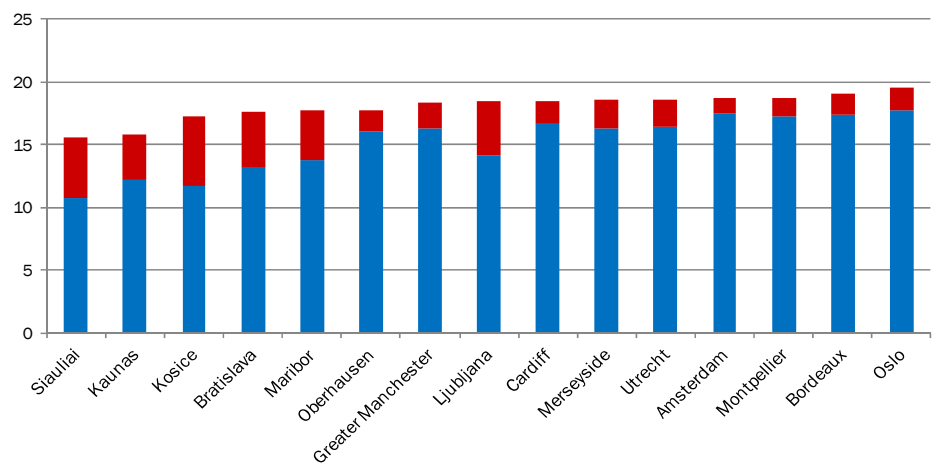

Life expectancy in poor health (remaining years)
Females Aged 15

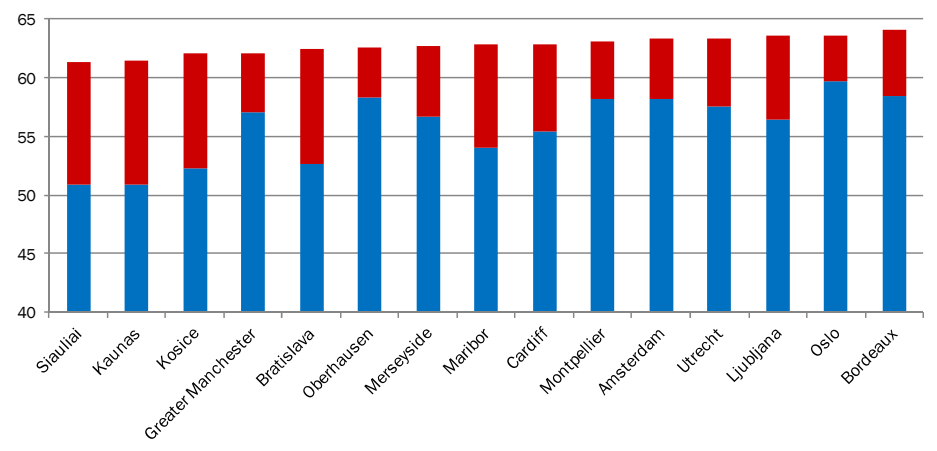

Females Aged 60

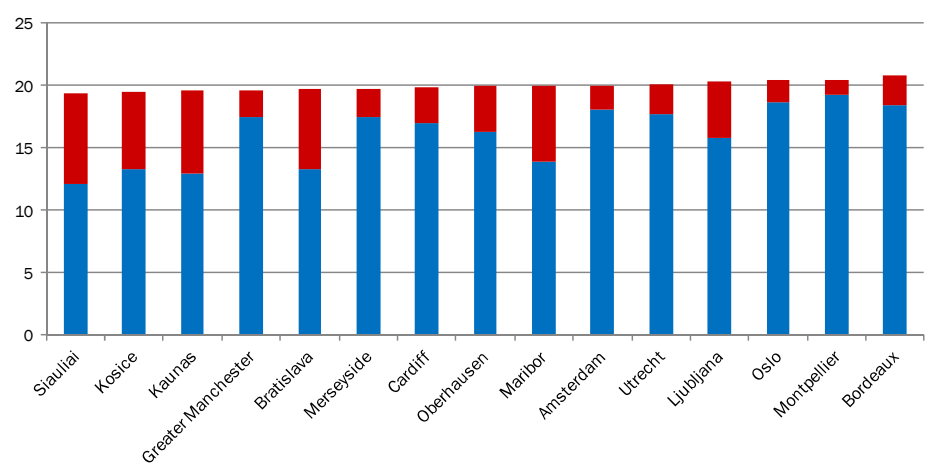

Life expectancy in good health (remaining years)

Figure 3. Healthy Life Expectancy

Presented here are estimates of healthy life expectancy (HLE) at ages 15 and 60 for men and women in eligible EURO-URHIS 2 urban areas. HLE was calculated first by estimating life expectancy at each age using recent 5-year averages of all-causes mortality for each urban area. From this, life expectancy was broken down into years living in good and poor perceived health, estimated using responses to the EURO-URHIS 2 adult survey question: How is your health in general?: Very good/Good/Fair/Bad/Very bad/Don't know, and the youth survey question: In general, would you say your health is..?: Excellent/Very Good/Good/Fair/Poor. Those answering very good, good or fair on the adult survey were classed as being in good perceived health, with the remainder in poor perceived health. For the youth survey, fair and poor were categorised as poor perceived health to match the scale applied to the adult survey. It was then possible to calculate the total years in good and poor perceived health and present this as a population level HLE. Full details on this process will be available in the final EURO-URHIS 2 project report, available at www.urhis.eu.

Male life expectancy in Merseyside at age 15 was 60.1 years. This was 1.7 years less than the highest in the sample (Oslo, 61.8 years), and 7.3 years more than the lowest (Kaunas, 52.8 years). At this age, males were estimated to spend 55.1 years in good perceived health. This is 3.6 years less than the longest HLE (Amsterdam, 58.7 years) and 10.0 years more than the shortest (Siauliai, 45.1 years).
Male life expectancy in Merseyside at age 60 was 18.6 years. This was 1.0 years less than the highest in the sample (Oslo, 19.6 years), and 3.0 years more than the lowest (Siauliai, 15.6 years). At this age, males were estimated to spend 16.3 years in good perceived health. This is 1.4 years less than the longest HLE (Oslo, 17.7 years) and 5.5 years more than the shortest (Siauliai, 10.8 years).

Female life expectancy in Merseyside at age 15 was 62.7 years. This was 1.4 years less than the highest in the sample (Bordeaux, 64.1 years), and 1.3 years more than the lowest (Siauliai, 61.4 years). At this age, females were estimated to spend 56.7 years in good perceived health. This is 3.0 years less than the longest HLE (Oslo, 59.7 years) and 5.8 years more than the shortest (Kaunas, 50.9 years).

Female life expectancy in Merseyside at age 60 was 19.8 years. This was 1.1 years less than the highest in the sample (Bordeaux, 20.9 years), and 0.5 years more than the lowest (Siauliai, 19.3 years). At this age, females were estimated to spend 17.5 years in good perceived health. This is 1.8 years less than the longest HLE (Montpellier, 19.3 years) and 5.4 years more than the shortest (Siauliai, 12.1 years). 


\section{MANCHESTER 1824}

The University of Manchester

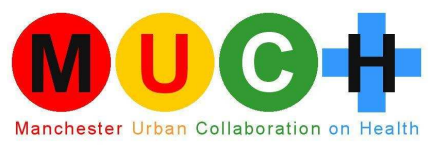

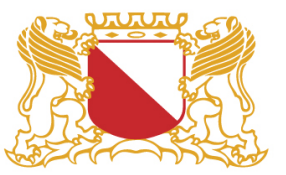

Gemeente Utrecht

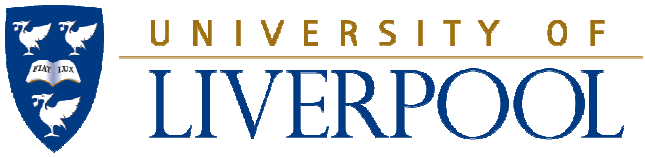

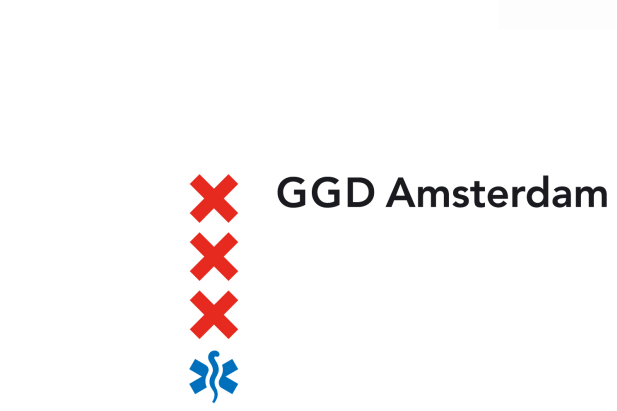

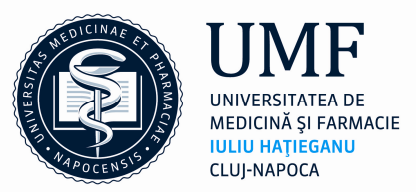

Norwegian Institute of Public Health

\section{Landeszentrum Gesundheit Nordrhein-Westfalen}
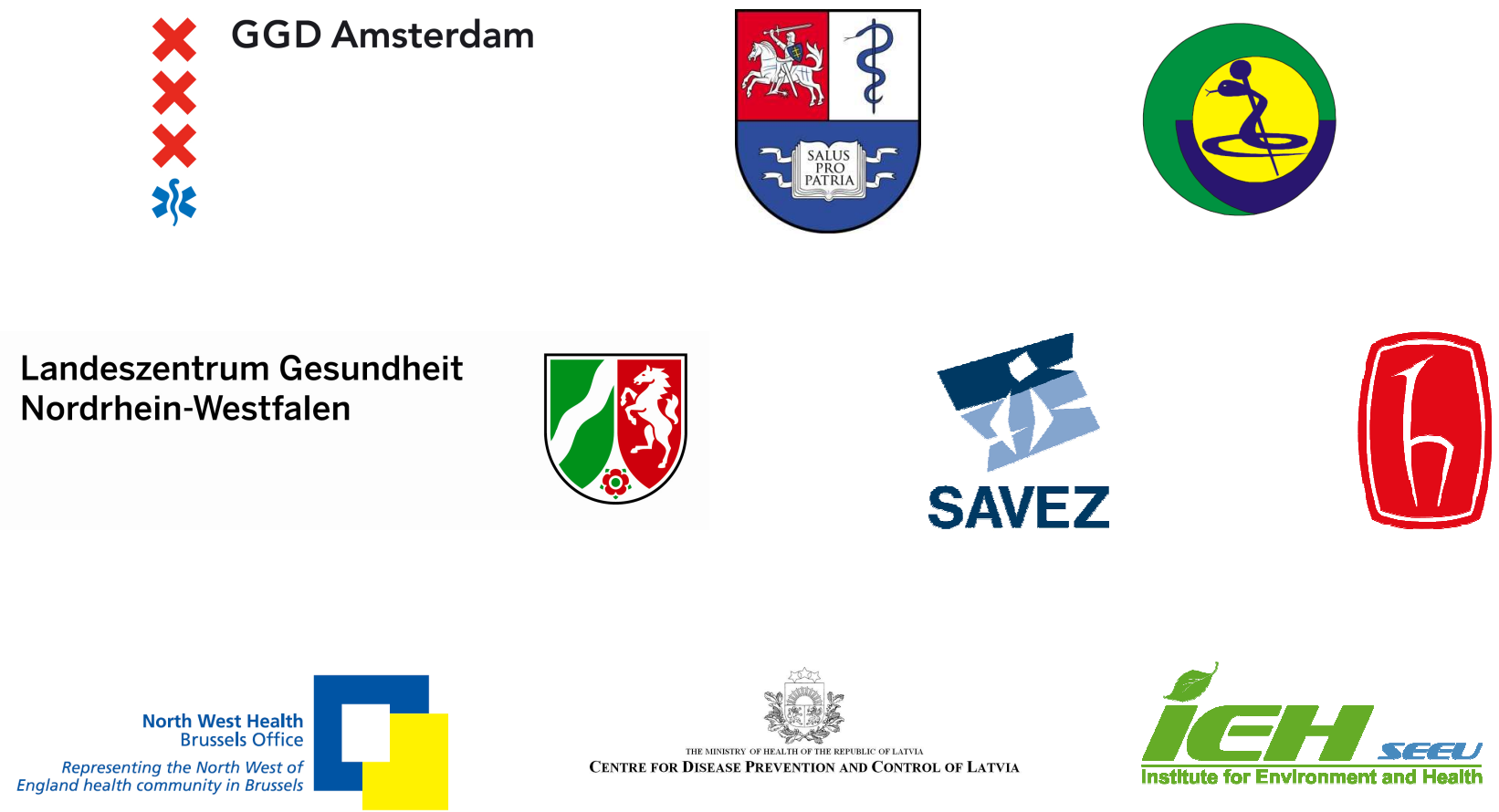

\section{F N O R S}

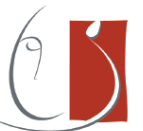

OBSERVATOIRE RÉGIONAL DE LA SANTÉ

\section{Languedoc-Roussillon}
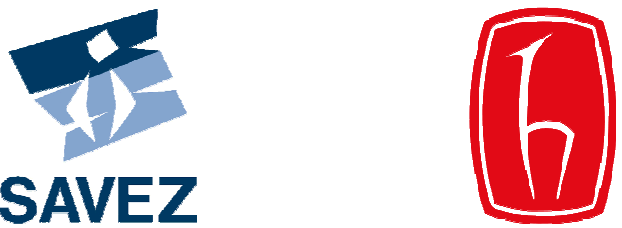

SAVEZ
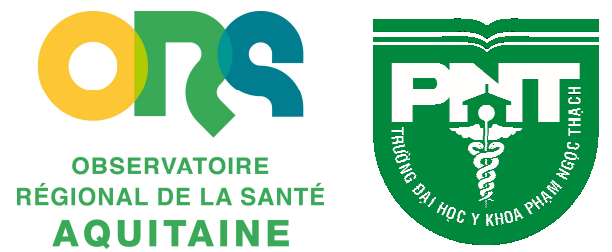

\section{Beneficiaries}

The University of Manchester; Municipal Health Service Utrecht; University of Liverpool; The luliu Hatieganu University of Medicine \& Pharmacy Epidemiology Department; The Norwegian Institute of Public Health; Municipal Health Service Amsterdam; Kaunas University of Medicine; Regional Public Health and Health Promotion Centre (Slovenia); Institute of Health and Work, North Rhine-Westphalia; Slovak Public Health Association; Hacettepe University, Department of Public Health; North West Regional Health Brussels Office; Latvian Public Health Agency; South East European University; National Federation of Regional Health Observatories; Pham Ngoc Thach University of Medicine 


\title{
Local EURO-URHIS 2 representative in Merseyside:
}

\author{
Dr Dan Pope \\ Division of Public Health \\ University of Liverpool \\ danpope@liv.ac.uk \\ +44 (0)1517945522
}
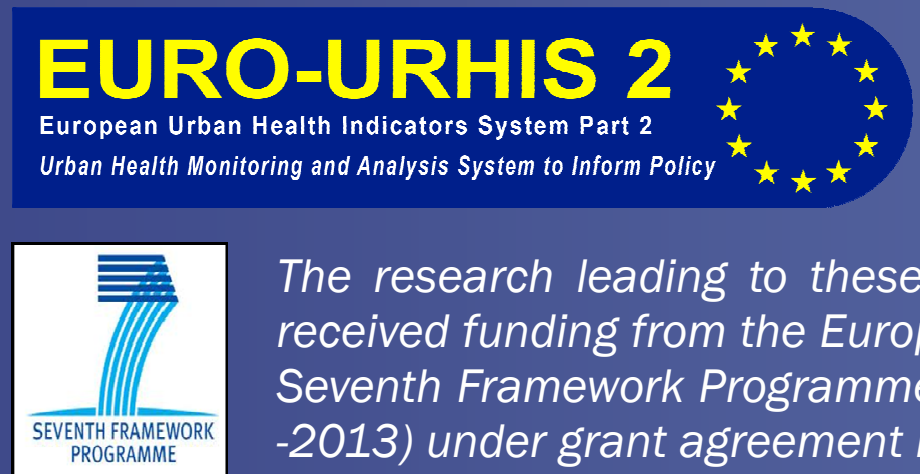

The research leading to these results has received funding from the European Union's Seventh Framework Programme (FP7/2007 -2013) under grant agreement no 223711

(c) EURO-URHIS 2, August 2012

Municipal Health Service Utrecht, The Netherlands

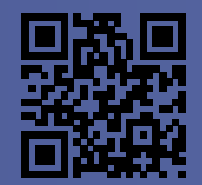

